\title{
A bifunctional metal/acid catalyst for one-pot multistep synthesis of pharmaceuticals
}

\author{
Maria Victoria Lopez-Prado, María J. Sabater*, Avelino Corma* \\ Instituto de Tecnología Química, Universitat Politècnica de València-Consejo \\ Superior de Investigaciones Cientificas, Av. los Naranjos, s/n, 46022 Valencia, Spain \\ *E-mail: acorma@itq.upv.es; mjsabate@itq.upv.es
}

Received November 25, 2019.

\begin{abstract}
One inhibitor of the fatty acid transporter FATP4 was synthesized in a three steps one-pot process in the presence of a bifunctional metal/acid catalyst. This molecule which has potential interest for the treatment of the obesity in orlistat (Xenical ${ }^{\mathrm{TM}}$ ) analogue-based therapies has a 3,4dihydropyrimidin-2(1H)-one (DHPM) scaffold and was obtained by means of a three one-pot process through successive oxidation, cyclocondensation and transesterification reactions. The one-pot strategy was extended to the synthesis of a series of related ester DHPM derivatives.
\end{abstract}

\section{Introduction}

3,4-Dihydropyrimidin-2(1H)-one derivatives (DHPMs) are molecules with a high potential for pharmaceutical applications such as anti-tumor, antiviral, anti-inflammatory activity, calcium channel blockers, antiparasitics, etc $[1-4,5]$.

There are several general methods for synthesizing these structures, and virtually none to get more complex derivatives in a straightforward manner [6].

Among the most modern methods to synthesize DHPMs, the Biginelli reaction is one of the most direct protocols, that involves the acid-catalyzed three-component condensation of ureas, aldehydes and $\beta$-oxoesters or 1,3-dicarbonyl compounds [6-8]. In general terms, when a particular derivative is needed, a preliminary basic DHPM structure is prepared which will lead to the target molecule with the required structure-activity relationship.

To date, several improved reaction protocols have been reported for the synthesis of basic DHPMs which include, the direct modification of the classical one-pot Biginelli approach itself, the implementation of novel, but more complex synthetic strategies, the benefits of using microwave heating, the use of a solid-phase method, alternative green solvents or even the nonuse of solvent, etc [9-27]. In this context, the use of reagents and catalysts supported on solid supports has received much attention in recent years because of the obvious simplification of the purification processes together with a drastic decrease in the production of waste and environmental impact [28-31].

In this line and going one step further, a more ambitious and less frequent addressed challenge is the synthesis of the dihydropyrimidinone ring (DHPM) and its ulterior derivatization in a single step $[32,33]$. 
For achieving this, the development of solid multifunctional catalysts which promotes the Biginelli reaction together with the direct derivatization of this N-heterocycle under green conditions is required. Therefore, in our aim to find multifunctional solid catalysts that allow process intensification, we have chosen the synthesis of a paradigmatic molecule that, while being pharmacologically relevant, it requires different steps for its preparation with the corresponding intermediate separation-purification procedures. This is the orlistat's (Xenical TM) functional analogue (5-cyclopentylcarbonyl-6-methyl-4-phenyl-3,4-dihydropyrimidin2(1H)-one) (1), an inhibitor of the fatty acid transporter FATP4 with potential interest for the treatment of the obesity, in orlistat analogue-based therapies (Scheme 1) [34].
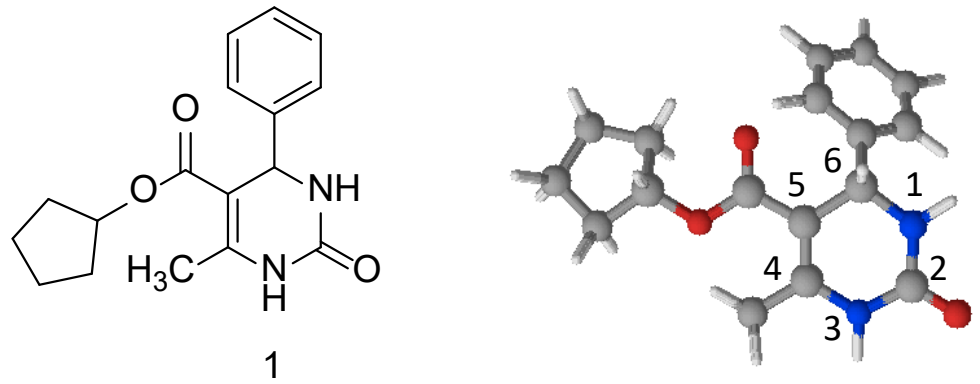

Scheme 1. Chemical structure and molecular modelization of the orlistat's functional analogue (5cyclopentylcarbonyl-6-methyl-4-phenyl-3,4-dihydropyrimidin2(1H)-one) (1).

This molecule, which has the 3,4-dihydropyrimidin-2(1H)-one scaffold and a lipophilic cyclopentyl ester group at the 5 position, will be obtained here through a three step one-pot reaction involving oxidation, cyclocondensation and transesterification reactions catalyzed by a bifunctional metal/acid catalyst as depicted in Scheme 2.<smiles>CCOC(=O)CC(C)=O</smiles>

Scheme 2 One-pot multistep catalytic process for the synthesis of dihydropyrimidin-2(1H)-one derivative 1 starting from benzyl alcohol. 
In a first approach benzaldehyde will be coupled with a $\alpha ß$-ketoester and urea to afford the dihydropyrimidin-2(1H)-one ring (the well-known Biginelli reaction). However, when stability or the handling of the aldehyde is an issue, the catalysts presented here allow starting the reaction from the corresponding alcohol that will be oxidized to generate "in situ" the aldehyde (steps A and B in Scheme 1). Thus, when the basic DHPM heterocycle is formed, the intermediate is transformed into a new dihydropyrimidin-2(1H)-one ester derivative through a transesterification reaction, still in a single pot multi-step process (step C, see Scheme 1).

We will show that this multi-step one-pot route can be performed with an optimized bifunctional metal/acid solid catalyst.

\section{Experimental}

Materials:

A commercially available starting materials, (alcohols, urea, ethyl aceto acetate, inorganic salts and carriers) were purchased from Sigma-Aldrich, Strem, Fluka and Nanoscale and were used without further purification. All solvents used for the synthesis were of HPLC grade. $\mathrm{Pd} / \mathrm{Al}_{2} \mathrm{O}_{3}$ was purchased from Aldrich.

\section{Synthesis of the catalysts}

\section{1. $\quad$ a) $P d(1 \%) / M C M 41$}

$\operatorname{Pd}(1 \%) / \operatorname{MCM} 41(\mathrm{Si} / \mathrm{Al}=12.5)$ was prepared according to a procedure reported in the literature [35]: MCM-41 ( $\mathrm{Si}: \mathrm{Al}=12.5)(1 \mathrm{~g}), \mathrm{PdCl}_{2}(16.8 \mathrm{mg})$ and $\mathrm{H}_{2} \mathrm{O}(50 \mathrm{ml})$ were mixed and stirred for 8 h. The solid was filtered, dried at $120^{\circ} \mathrm{C}$ and calcined at $400^{\circ} \mathrm{C}$ for $2 \mathrm{~h}$. The final catalyst was hidrogenated during $2 \mathrm{~h}$ at $200^{\circ} \mathrm{C}$ (hydrogen flow: $100 \mathrm{ml} / \mathrm{min}$ ).

\section{2. $\quad$ b) $\mathrm{Pd}(1 \%) / \mathrm{Al}_{2} \underline{\mathrm{O}}_{3}$}

$\mathrm{Pd} / \mathrm{Al}_{2} \mathrm{O}_{3}$ was purchased by Aldrich.

\section{3. $\quad \underline{c) P d(0.5 \%) / H \beta}$}

The catalyst was prepared following procedure reported in the literature [36]: $\mathrm{PdCl}_{2}(8.4 \mathrm{mg})$ and $\mathrm{NH}_{4} \mathrm{OH}(12.5 \mathrm{ml}, 0.1 \mathrm{M})$ were mixed and stirred at room temperature for $24 \mathrm{~h}$ in the presence of 
$\mathrm{H} \beta(2.5 \mathrm{~g})$ (PQ Corporation). The resulting solid was filtered, washed with distilled water $(1 \mathrm{~L} / \mathrm{g})$, and dried in an oven at $100^{\circ} \mathrm{C}$ overnight.

\section{4. $\quad \underline{P d(0.5 \%) / I T Q-2}$}

The delaminated material ITQ-2 was prepared following procedure reported in the literature [3739]. Then ITQ-2 (1g) was mixed with an excess of $\mathrm{HCl}(0.2 \mathrm{M} ; 3 \mathrm{ml} / \mathrm{g} \mathrm{MCM} 41)$ and $\mathrm{PdCl}_{2}(8.4$ $\mathrm{mg}$ ). The slurry was stirred for $24 \mathrm{~h}$. The solid was filtered, dried at $100^{\circ} \mathrm{C}$ overnight and calcined at $350^{\circ} \mathrm{C}$ for $3 \mathrm{~h}$. Finally the catalyst was hidrogenated at $350^{\circ} \mathrm{C}$ for $1 \mathrm{~h}$ (hydrogen flow: $100 \mathrm{~mL} / \mathrm{min})$.

\section{5. $\quad \underline{P d}(0.5 \%) /$ Amberlyst and $P d(1 \%) /$ Amberlyst}

The catalyst was prepared by following the procedure reported in the literature [40]: the required amount of $\mathrm{Pd}\left(\mathrm{NH}_{3}\right)_{4} \mathrm{Cl}$, deionized water $(20 \mathrm{ml})$ and Amberlyst-15 (1g) (Fluka, 20-50 mesh) were mixed and stirred at $80^{\circ} \mathrm{C}$ for $24 \mathrm{~h}$. The solid was filtered, washed with deionized water $(15 \mathrm{~mL})$, and dried at $100^{\circ} \mathrm{C}$ overnight. The as-made material thus obtained was reduced under an $\mathrm{H}_{2}$ flow $(100 \mathrm{~mL} / \mathrm{min})$ at $100^{\circ} \mathrm{C}$ for $1 \mathrm{~h}$ just before use.

\section{6. $\quad \underline{P d}(n \%) / S A C-13(n=0.25,0.5 \%$ and $1 \%)$}

The required amount of $\mathrm{Pd}\left(\mathrm{NH}_{3}\right)_{4} \mathrm{NO}_{2}$, solvent $(10 \mathrm{ml})$ and commercial SAC-13 (1 g) (Aldrich) were mixed and stirred at $80^{\circ} \mathrm{C}$ for $24 \mathrm{~h}$ after which the catalyst was filtered off, washed and dried at $100^{\circ} \mathrm{C}$ under air. The obtained material was subsequently reduced at $200^{\circ} \mathrm{C}$ (heating rate $\left.5^{\circ} \mathrm{C} / \mathrm{min}\right)$ under $\mathrm{H}_{2}$ flow $(100 \mathrm{~mL} / \mathrm{min})$.

\section{7. $\quad \underline{P d(0.5 \%) / P V S-S i O_{2}}$}

PVS-SiO 2 was prepared according to a reported procedure [41, 42]. Then $\mathrm{PdCl}_{2}(8.4 \mathrm{mg}), \mathrm{H}_{2} \mathrm{O}(10$ $\mathrm{ml})$ and $\mathrm{PVS}_{-} \mathrm{SiO}_{2}(1 \mathrm{~g})$ were mixed and stirred at $80^{\circ} \mathrm{C}$ for $24 \mathrm{~h}$, after which the catalyst was filtered off, washed and dried at $100^{\circ} \mathrm{C}$ under air. The material was subsequently reduced at $200^{\circ} \mathrm{C}$ (heating rate $\left.5^{\circ} \mathrm{C} / \mathrm{min}\right)$ under $\mathrm{H}_{2}$ flow $(100 \mathrm{~mL} / \mathrm{min})$. 
Characterization of the catalysts

1) Table 1S: Metal content (\% weight), BET specific surface area $\left(\mathrm{m}^{2} \cdot \mathrm{g}^{-1}\right)$ and average particle size $(\mathrm{nm})$ of different catalysts.

\begin{tabular}{|c|c|c|c|c|}
\hline Catalyst & $\begin{array}{l}\text { Nominal } \\
\text { Metal } \\
\text { content } \\
\text { (\%weight) }\end{array}$ & $\begin{array}{c}\text { Metal } \\
\text { content } \\
(\% \text { weight })^{\mathrm{a}}\end{array}$ & ABET(m2.g-1) & $\mathbf{D}(\mathbf{n m})^{\mathbf{b}}$ \\
\hline $\mathrm{Pd}(0.5 \%) / \mathrm{MCM} 41(\mathrm{Si} / \mathrm{Al}: 15)$ & 0.5 & 1 & 967 & 8 \\
\hline $\mathrm{Pd}(1 \%) / \mathrm{Al}_{2} \mathrm{O}_{3}$ & 1 & 1 & 89 & 5 \\
\hline $\mathrm{Pd}(0.5 \%) / \mathrm{H} \beta(\mathrm{Si} / \mathrm{Al}: 12.5)$ & 0.5 & 0.5 & 580 & 8 \\
\hline $\operatorname{Pd}(0.5 \%) / \mathrm{ITQ}-2(\mathrm{Si} / \mathrm{Al}: 12.5)$ & 0.5 & 0.5 & 635 & 6 \\
\hline $\operatorname{Pd}(1 \%) /$ Amberlyst & 1 & 1 & 50 & 32 \\
\hline $\mathrm{Pd}(0.5 \%) /$ Amberlyst & 0.5 & 0.5 & 52 & 9 \\
\hline $\mathrm{Pd}(0.25 \%) / \mathrm{SAC}-13$ & 0.25 & 0.3 & 219 & 4 \\
\hline $\mathrm{Pd}(0.5 \%) / \mathrm{SAC}-13$ & 0.5 & 0.5 & 215 & 6 \\
\hline $\mathrm{Pd}(1 \%) / \mathrm{SAC}-13$ & 1 & 1 & 202 & 7 \\
\hline $\mathrm{Pd}(0.5 \%) / \mathrm{PVS}-\mathrm{SiO}_{2}$ & 0.5 & 0.5 & 297 & 7 \\
\hline $\mathrm{Pd}(0.5 \%) / \mathrm{CeO}_{2}$ & 0.5 & 0.5 & 246 & 6 \\
\hline $\mathrm{Pd}(0.5 \%) / \mathrm{ZrO}_{2}$ & 0.5 & 0,5 & 137 & 5 \\
\hline
\end{tabular}

a) Analyzed by ICP; b) Average metal particle size analyzed by HR-TEM 


\section{2) HRTEM analysis: size distribution}
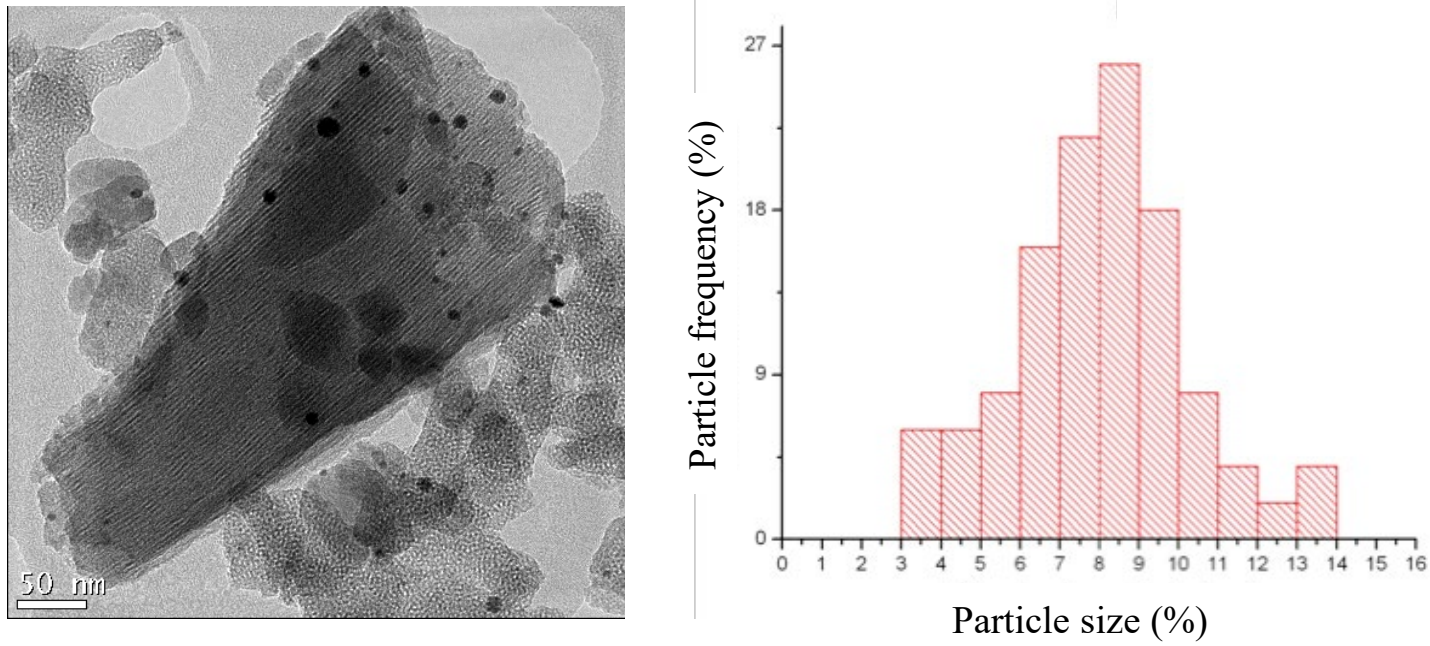

Figure 1S. Pd(0.5\%)/MCM41 (Si/Al:15) HR-TEM micrography and particle size histogram.
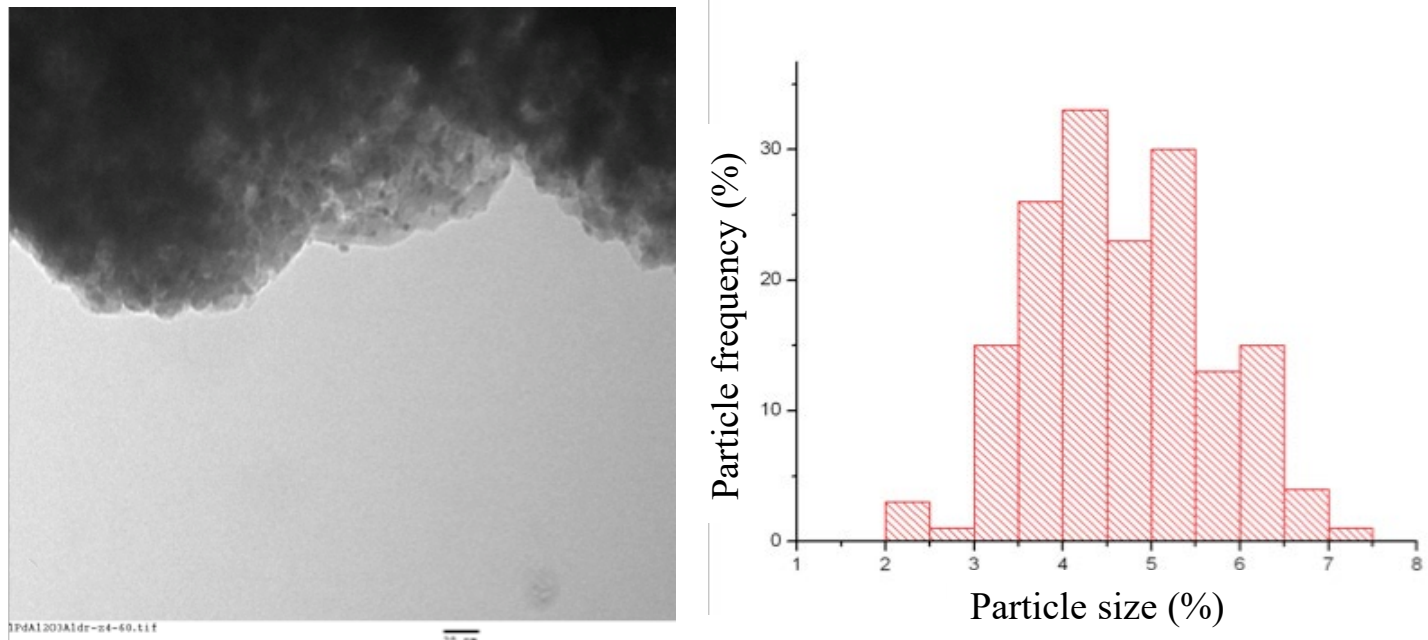

Figure $2 \mathrm{~S} . \mathrm{Pd}(1 \%) / \mathrm{Al}_{2} \mathrm{O}_{3}$ HR-TEM micrography and particle size histogram. 

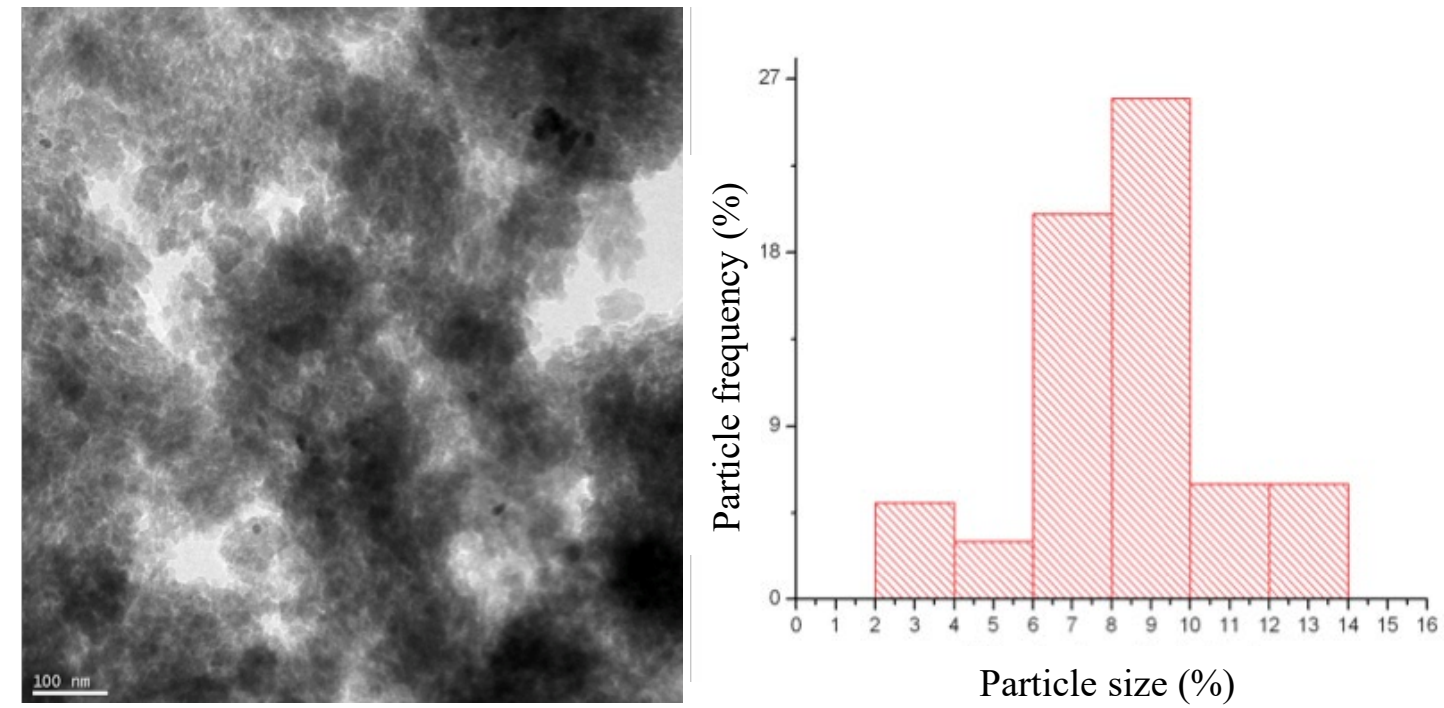

Figure $3 \mathrm{~S} . \mathrm{Pd}(0.5 \%) / \mathrm{H} \beta(\mathrm{Si} / \mathrm{Al}: 12.5) \mathrm{HR}-\mathrm{TEM}$ micrography and particle size histogram.
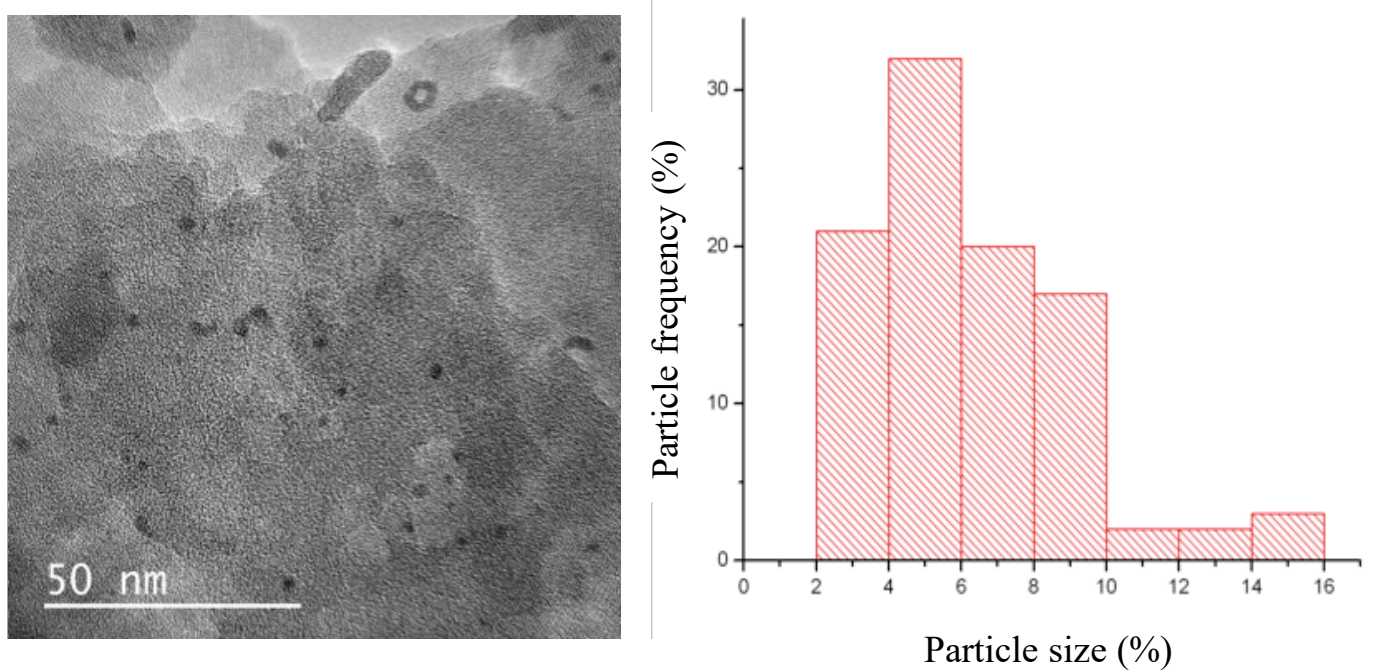

Figure 4S. $\operatorname{Pd}(0.5 \%) /$ ITQ-2 (Si/Al:12.5) HR-TEM micrography and particle size histogram. 

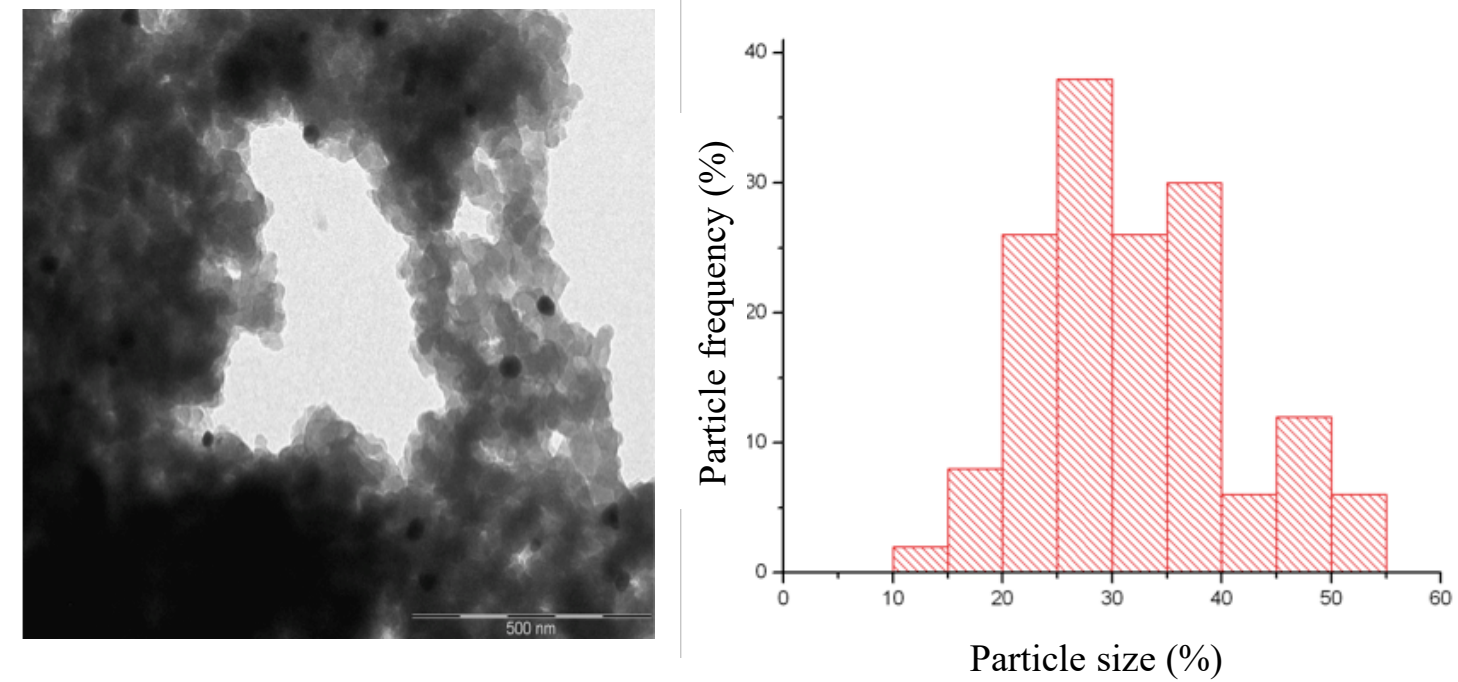

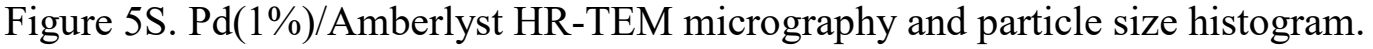
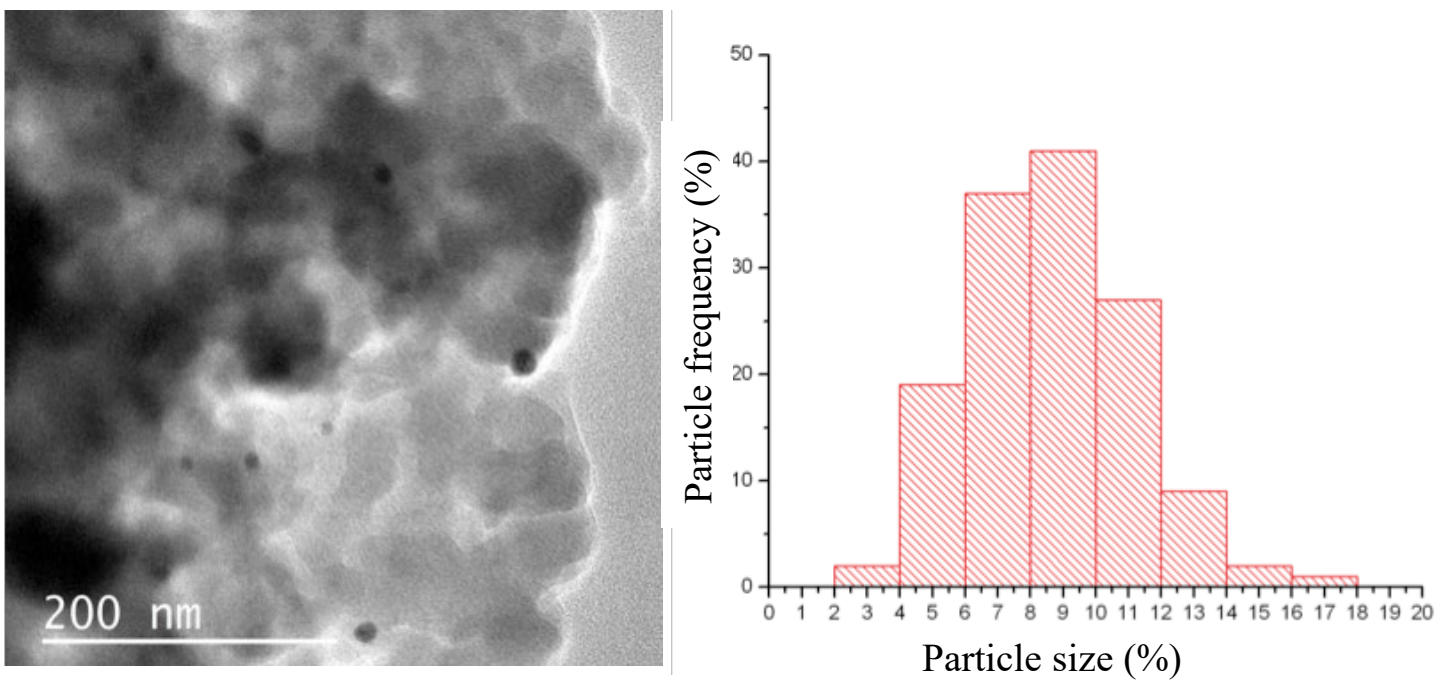

Figure $6 \mathrm{~S} . \mathrm{Pd}(0.5 \%) /$ Amberlyst HR-TEM micrography and particle size histogram. 

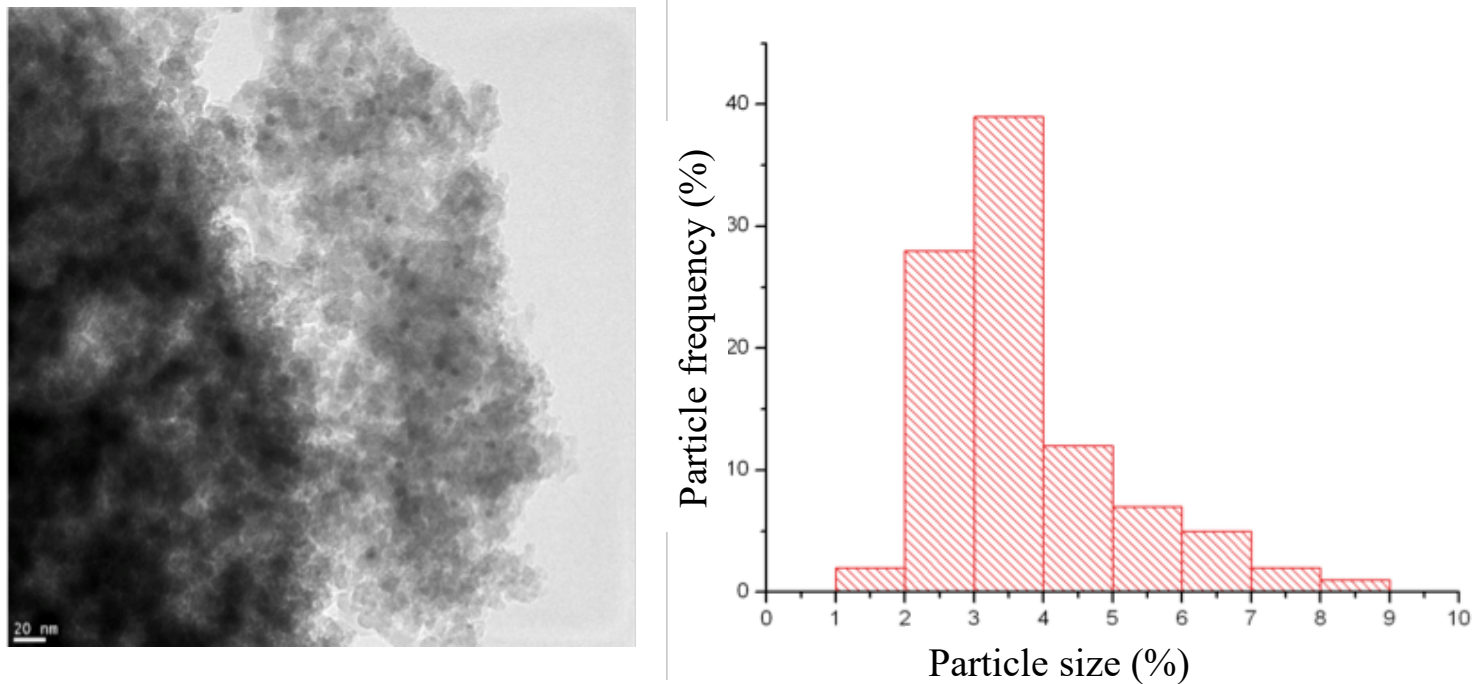

Figure $7 \mathrm{~S} . \mathrm{Pd}(0.25 \%) / \mathrm{SAC}-13$ HR-TEM micrography and particle size histogram.
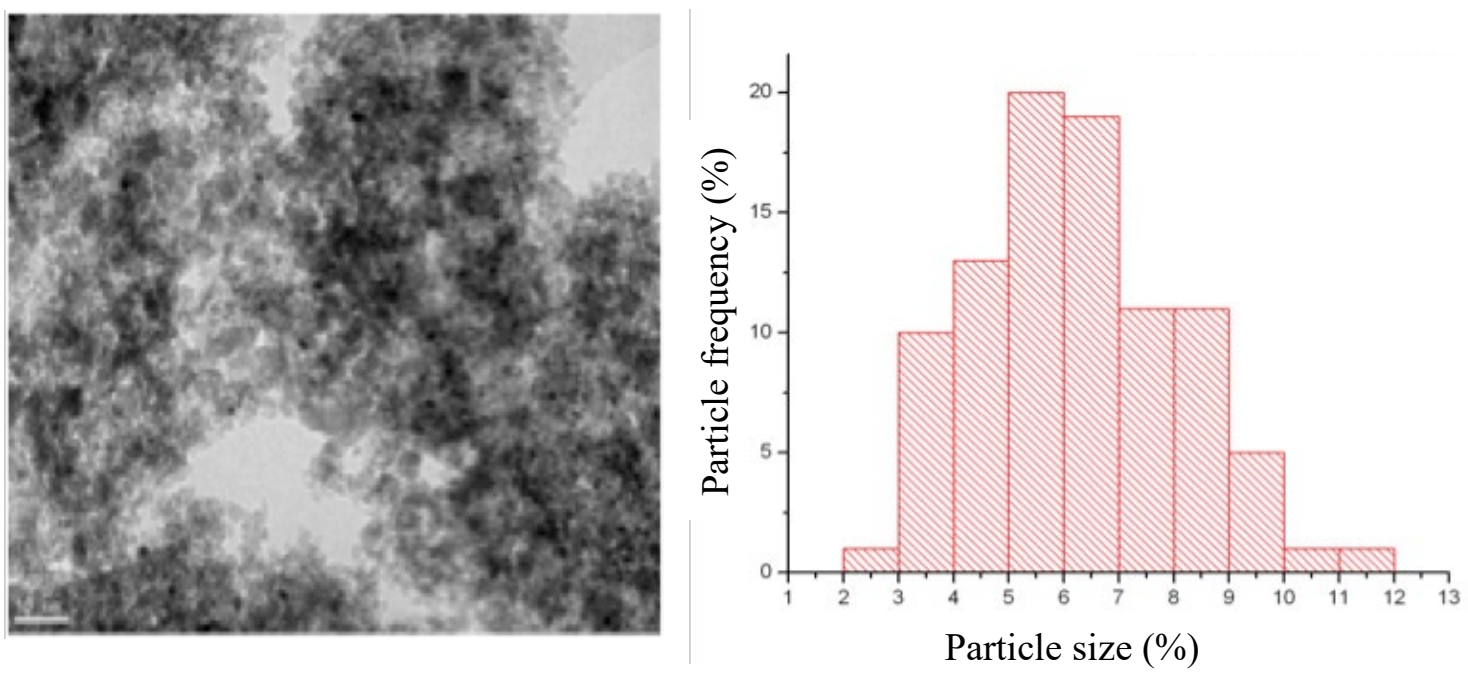

Figure $8 \mathrm{~S} . \operatorname{Pd}(0.5 \%) / \mathrm{SAC}-13 \mathrm{HR}-\mathrm{TEM}$ micrography and particle size histogram. 

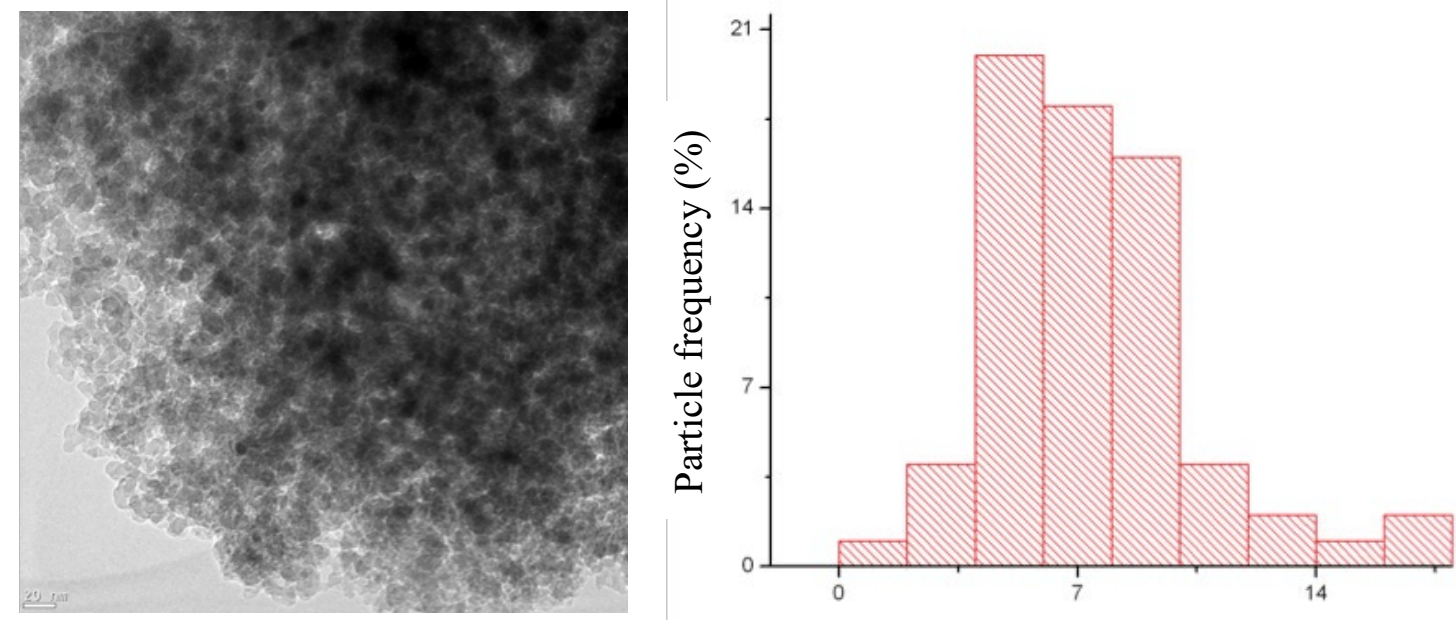

Particle size (\%)

Figure 9S. Pd(1.0\%)/SAC-13 HR-TEM micrography and particle size histogram.
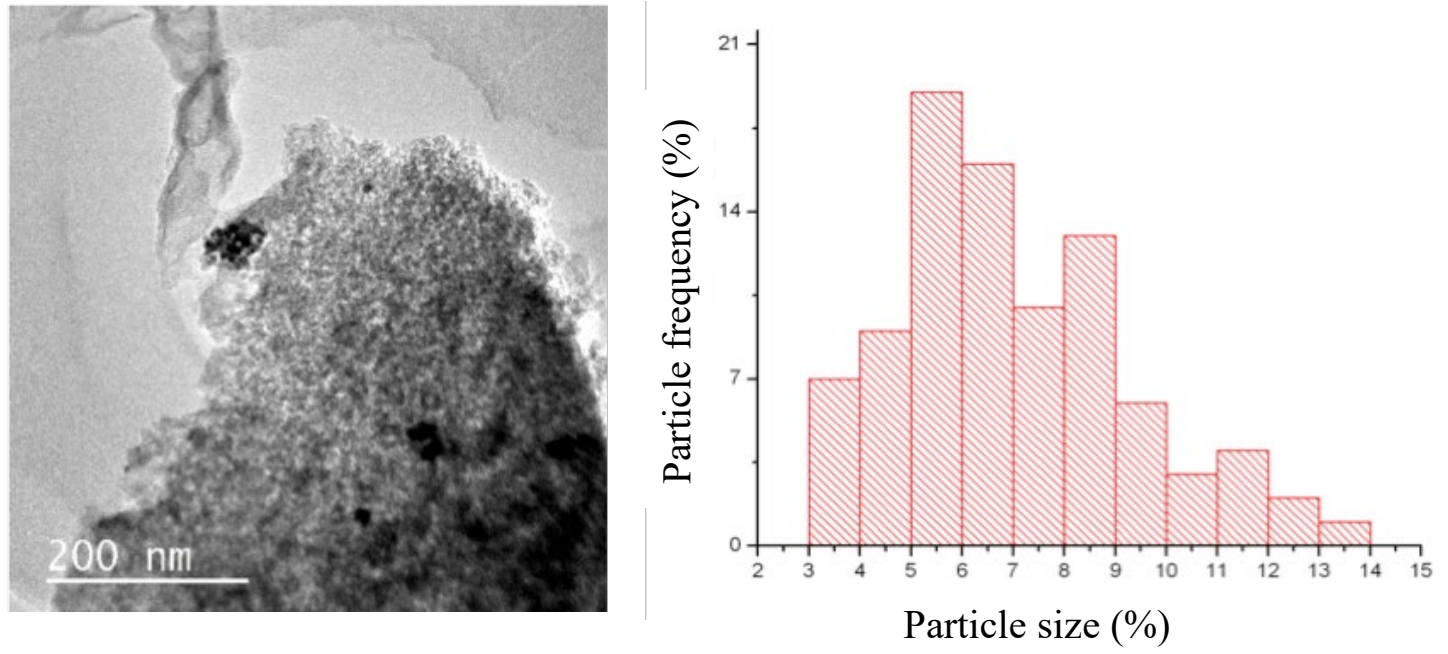

Figure $10 \mathrm{~S} . \mathrm{Pd}(0.5 \%) / \mathrm{PVS}_{-} \mathrm{SiO}_{2} \mathrm{HR}-\mathrm{TEM}$ micrography and particle size histogram. 

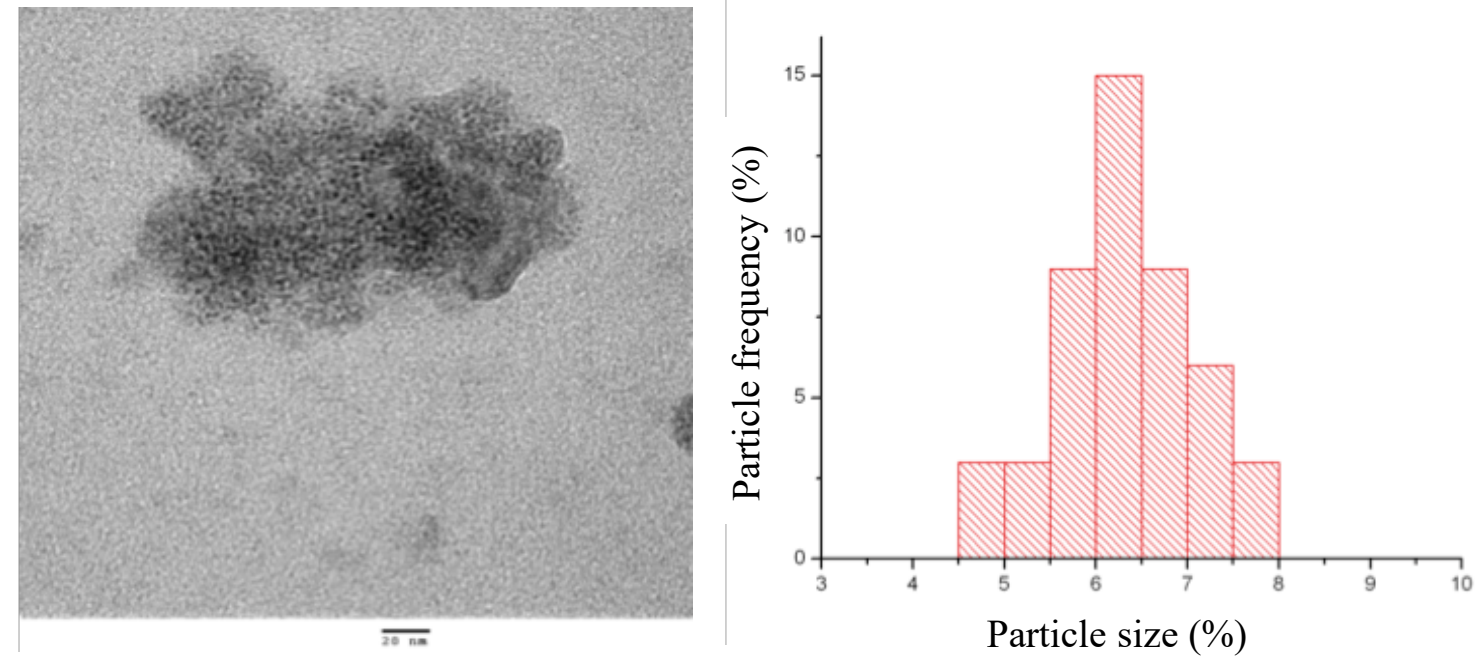

Figure $11 \mathrm{~S} . \mathrm{Pd}(0.5 \%) / \mathrm{CeO}_{2} \mathrm{TEM}$ micrography and particle size histogram.
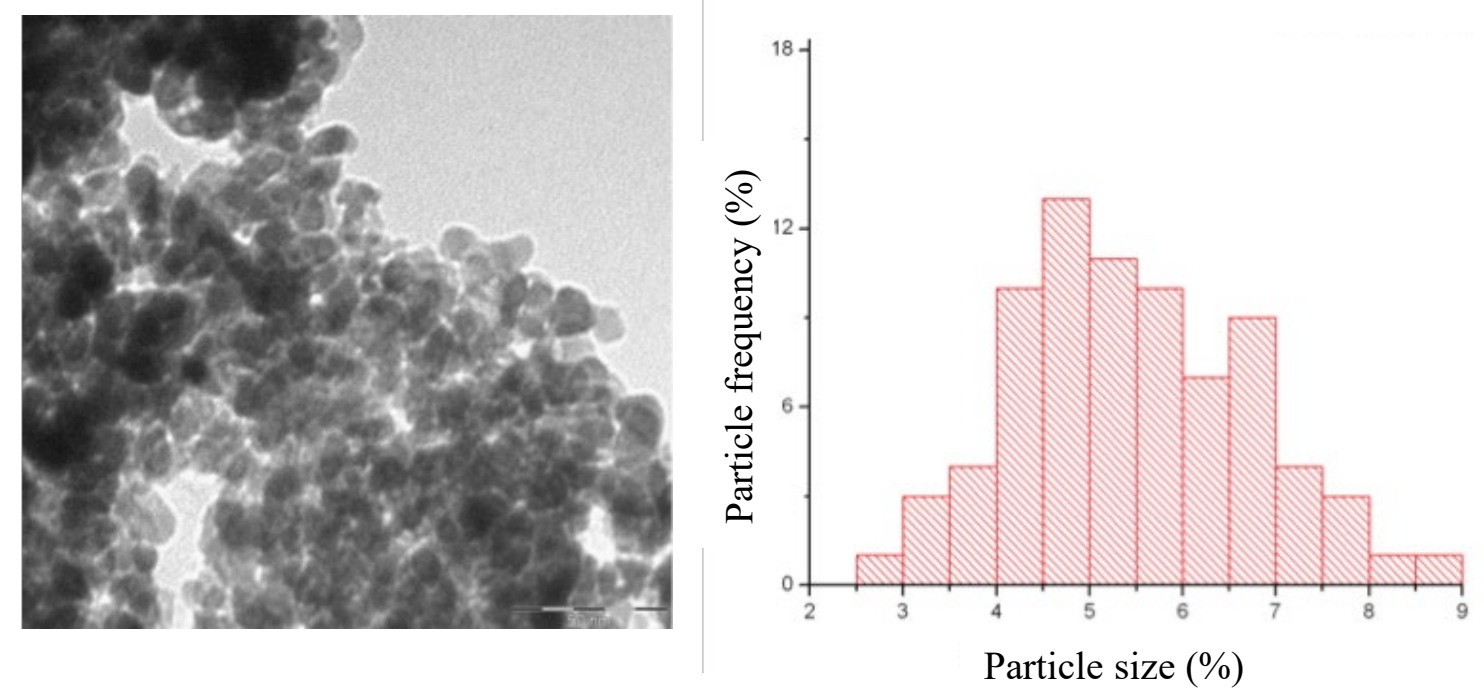

Figure $12 \mathrm{~S} . \mathrm{Pd}(0.5 \%) / \mathrm{ZrO}_{2} \mathrm{TEM}$ micrography and particle size histogram. 


\section{$\underline{\text { Catalytic reactions }}$}

1. One pot reaction for the synthesis of DHPMs

A mixture of alcohol (1 mmol), catalyst (1\% mol Pd), trifluorotoluene $(1 \mathrm{~mL})$, and $\mathrm{n}$ dodecane $(0.25 \mathrm{mmol})$ as internal standard were placed in a batch microreactor being vigorously stirred at $100^{\circ} \mathrm{C}$ under 5 bar $\mathrm{O}_{2}$ pressure. Once the oxidation of the alcohol was completed, ethyl acetoacetate $(1 \mathrm{mmol})$ and urea $(1.3 \mathrm{mmol})$ were incorporated into the vessel, the temperature was decreased to $80^{\circ} \mathrm{C}$ and the reaction was monitored by $\mathrm{GC}$ until reaction completion.

2. One pot reaction for the synthesis of compounds 6-10

A mixture of alcohol ( $1 \mathrm{mmol})$, catalyst $(1 \% \mathrm{~mol} \mathrm{Pd})$, trifluorotoluene $(1 \mathrm{~mL})$, and $\mathrm{n}$ dodecane $(0.25 \mathrm{mmol})$ as internal standard were placed in a batch microreactor being vigorously stirred at $100^{\circ} \mathrm{C}$ under 5 bar $\mathrm{O}_{2}$ pressure. Once the oxidation of the alcohol was completed, ethyl acetoacetate $(1 \mathrm{mmol})$ and urea $(1.3 \mathrm{mmol})$ were incorporated into the vessel, the temperature was decreased to $80^{\circ} \mathrm{C}$ and the reaction was monitored by $\mathrm{GC}$ until reaction completion.

Then phosphotungstic acid PTA (1.75\% mol with respect to the amount of DHPM formed) an alcohol excess were added and the temperature was increased up to $140^{\circ} \mathrm{C}$. The reaction was monitored by GC. When the reaction was completed, the catalyst was separated by filtration and the solvent was evaporated under vacuo. The reaction product was purified by column chromatography on silica gel with a mixture hexane/Et ${ }_{2} \mathrm{O}(99: 1)$ as eluent.

\section{Results and Discussion}

Study of the bifunctional metal/acid catalyst for the synthesis of the DHPM scaffold.

The possibility of developing a one-pot methodology for the synthesis of the DHPM ester derivative 1 became evident to us by considering the retrosynthetic analysis of the molecule (Scheme 3). 


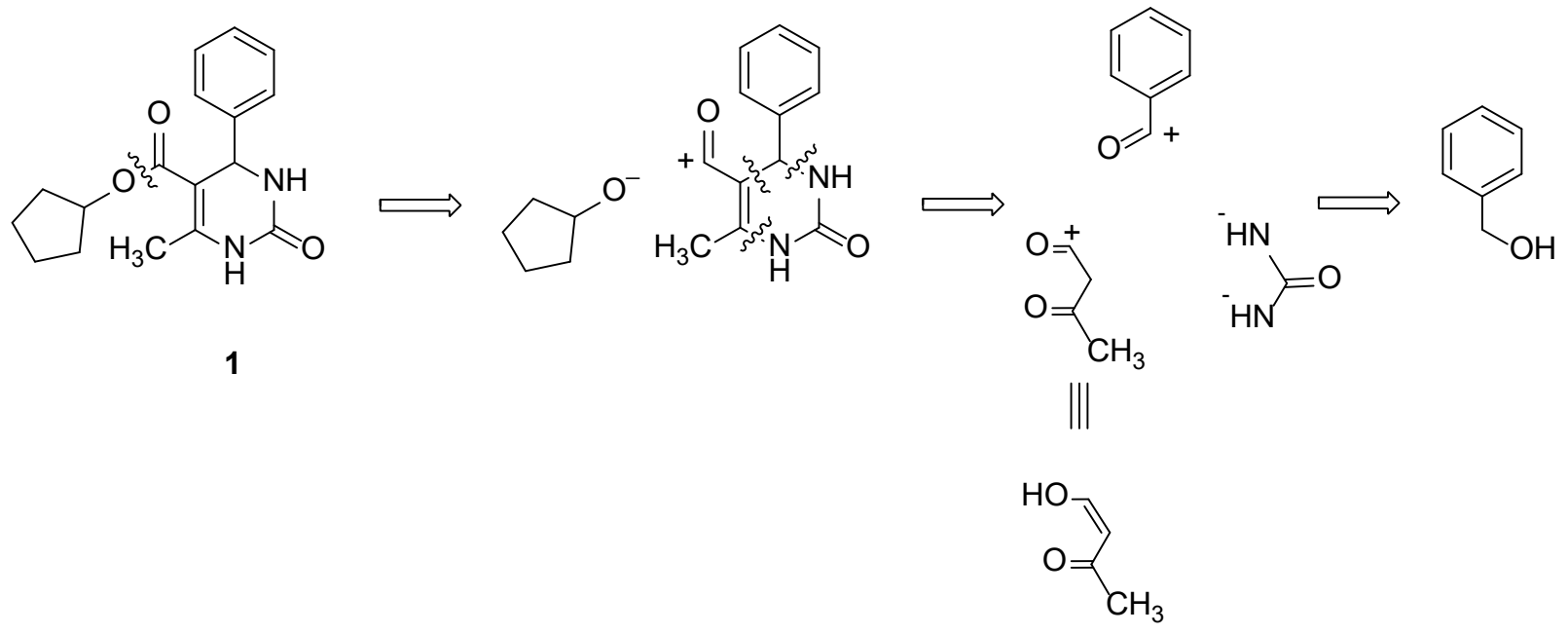

Scheme 3 Retrosynthetic analysis of bioactive structure (5-cyclopentylcarbonyl-6-methyl-4phenyl-3,4-dihydropyrimidin2(1H)-one) (1).

According to scheme 3 our target molecule 1 might be transformed into two much simpler synthons derived from a nucleophilic cyclopentanoxide anion and a primary DHPM ring (Scheme 3). This DHPM nucleous might be obtained through three key disconnections that correspond to a known acid catalyzed three-component condensation strategy between an aldehyde, $\alpha, \beta$-ketoester and urea denoted as Biginelli reaction (Scheme 3). Thus, our goal was the preparation of this DHPM ester 1 by planning the synthesis forward and using a bifunctional catalyst (Scheme 2). The catalyst should contain an acidic and a metal function. The acid should be capable of assembling the original three components (urea, oxoester and aldehyde) into the N-heterocycle DHPM, and the metal function would allow starting the reaction from the corresponding alcohol and to dehydrogenate it into the aldehyde. This can be of interest when the aldehyde is not stable under reaction conditions or it is less available (see Scheme 2).

To perform the alcohol dehydrogenation reaction we thought on palladium nanoparticles supported on a high surface area solid acid. The choice of the above metal allows using molecular oxygen as green oxidant in an oxidative dehydrogenation of the alcohol to the aldehyde [44-51], while the solid acid support would catalyze the consecutive cyclocondensation or Biginelli reaction leading to the final product DHPM (Scheme 2). Preliminary tests revealed that the catalytic results improved when the urea and $\alpha, \beta$-ketoester reactants were incorporated sequentially after completing the formation of benzaldehyde, instead of adding the three components simultaneously. Thus, taking into account these preliminary results, the experimental procedure was adapted so that the urea and the $\alpha, \beta$-ketoester were incorporated once the alcohol was completely reacted. 
In principle, since a solid with acid sites is required, and taking into account the large size of the products, a structured mesoporous aluminosilicate MCM-41 $(\mathrm{Si} / \mathrm{Al}=15)$ was selected as the solid acidic component of the bifunctional catalyst [52]. Then palladium was deposited on MCM-41 and the resulting catalyst $\mathrm{Pd}(1 \%) / \mathrm{MCM} 41(\mathrm{Si} / \mathrm{Al}=15)$ was tested for the benzyl alcohol, urea and ethyl acetoacetate assembly to form 2-methyl-3-ethylformiate-4-phenyl-3,4dihydropyrimidin-2(1H)-one (1) in TFT as solvent (entry 1, Table 1).

Table 1 Results on the concurrent tandem oxidation/cyclization reaction to 2-methyl-3ethylformiate-4-phenyl-3,4-dihydropyrimidin-2(1H)-one (1) in TFT.

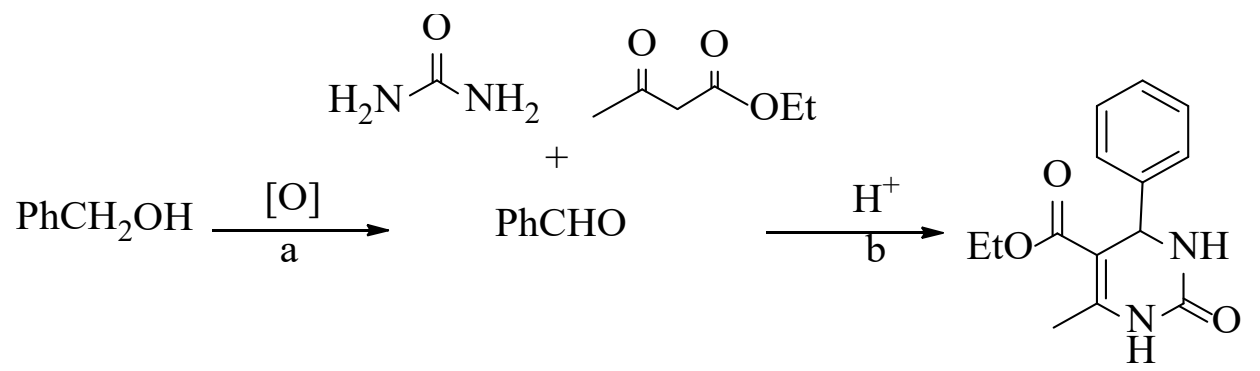

1

\begin{tabular}{|c|c|c|c|c|c|}
\hline \multirow[t]{2}{*}{ Entry } & \multirow[t]{2}{*}{ Catalyst } & \multicolumn{2}{|l|}{ Step $\mathbf{a}^{\mathrm{a}}$} & \multicolumn{2}{|l|}{ Step $\mathbf{b}^{\mathrm{b}}$} \\
\hline & & $\operatorname{Conv}(\%)^{\mathrm{c}}$ & $\mathrm{S}(\%)^{\mathrm{d}}$ & $\operatorname{Conv}(\%)^{\mathrm{e}}$ & $S(\%)^{f}$ \\
\hline 1 & $\mathrm{Pd}(1 \%) / \mathrm{MCM} 41$ (Si/Al:15) & 73 & 95 & 51 & 50 \\
\hline 2 & $\mathrm{Pd}(1 \%) / \mathrm{Al}_{2} \mathrm{O}_{3}$ & 90 & 95 & 81 & 70 \\
\hline 3 & $\mathrm{Pd}(0.5 \%) / \mathrm{H} \square \square(\mathrm{Si} / \mathrm{Al}: 12.5)$ & 95 & 95 & 85 & 67 \\
\hline 4 & $\operatorname{Pd}(0.5 \% / \mathrm{ITQ}-2(\mathrm{Si} / \mathrm{Al}: 12.5)$ & 85 & 62 & 97 & 94 \\
\hline 5 & $\operatorname{Pd}(1 \%) /$ Amberlyst & 99 & 5 & - & - \\
\hline 6 & $\operatorname{Pd}(0.5 \%) /$ Amberlyst & 83 & 65 & 67 & 81 \\
\hline 7 & $\operatorname{Pd}(0.25 \%) / \mathrm{SAC}-13$ & 99 & 90 & 89 & 81 \\
\hline 8 & $\mathrm{Pd}(0.5 \%) / \mathrm{SAC}-13$ & 99 & 99 & 93 & 95 \\
\hline 9 & $\operatorname{Pd}(1 \%) / \mathrm{SAC}-13$ & 99 & 99 & 87 & 91 \\
\hline 10 & $\mathrm{Pd}(0.5 \%) / \mathrm{PVS}-\mathrm{SiO}_{2}$ & 89 & 99 & 92 & 89 \\
\hline 11 & $\mathrm{Pd}(0.5 \%) / \mathrm{CeO}_{2}$ & 95 & 99 & 63 & 65 \\
\hline 12 & $\mathrm{Pd}(0.5 \%) / \mathrm{ZrO}_{2}$ & 96 & 86 & 62 & 58 \\
\hline
\end{tabular}


a)Reaction conditions: alcohol $(1 \mathrm{mmol})$, TFT $(1 \mathrm{~mL})$, catalyst $(1 \% \mathrm{~mol} \mathrm{Pd}), \mathrm{n}$-dodecane $(0.25$ $\mathrm{mmol}), \mathrm{P}_{\mathrm{O} 2}=5$ bar, $\left.\mathrm{T}=100^{\circ} \mathrm{C} ; \mathrm{b}\right)$ reaction conditions: ethyl acetoacetate $(1 \mathrm{mmol})$, urea $(1.3$ mmol), $\mathrm{T}=80^{\circ} \mathrm{C}, \mathrm{N}_{2} ; \mathrm{c}$ ) conversion (\%) determined by $\mathrm{GC}$ on the amount of benzyl alcohol converted; d) selectivity (\%); e) conversion (\%): determined on the amount of benzaldehyde transformed; f) selectivity $(\%)$.

In this case the catalyst was active and selective for performing the oxidative dehydrogenation step (step a), but its activity and selectivity was low for the cyclocondensation reaction step (step b) (entry 1 , Table 1). Notice that even $\mathrm{Pd}$ on $\gamma-\mathrm{Al}_{2} \mathrm{O}_{3}$ was a very suitable catalyst for step a, and again better than Pd/MCM41 for step b (entry 2, Table 1).

At this point we decided to modify the acidic component of the catalyst increasing the acidity by using a large pore high silica zeolite such as Beta, and to disperse Pd on the surface. For achieving high Pd dispersions we followed the method of Zhang el al. [53]. The resulting catalyst $\operatorname{Pd}(0.5 \%) / \mathrm{H} \beta$ was activated previously by calcination at $200^{\circ} \mathrm{C}$ for $3 \mathrm{~h}$ followed by reduction at $200^{\circ} \mathrm{C}$ during $3 \mathrm{~h}$ with $\mathrm{H}_{2}$. The catalytic results in the two- step one-pot reaction in the presence of $\operatorname{Pd}(0.5 \%) / H \beta$ slightly increased though the selectivity in the second step did not improve probably due to steric limitations (entry 3, Table 1). Therefore, it was decided to increase the reactant accessibility, while maintaining a zeolitic acidity. For achieving this, palladium was supported on a highly stable layered zeolite precursor having structured readily accessible external cups, as it is the case of ITQ-2 zeolite [54]. ITQ-2 was prepared with a Si/Al ratio of 12.5 [54]. In this case the increased access to the catalytic sites for large molecules contributed to improve the catalytic results in the second step of the one-pot reaction, although it was not so for the oxidation step (step a) since in this case the results were significantly lower than those obtained with zeolite $\beta$ (entry 4 , Table 1).

Besides this and in the search for new acid catalysts, organic polymers with strong acidities such as Amberlyst-15 were also tested with two different Pd loadings [55, 56]. Unfortunately, with the highest metal loading $(1 \% \mathrm{Pd})$ the metal dispersion achieved on this sulfonic resin was very low due to the low surface area of Amberlyst-15 $\left(45 \mathrm{~m}^{2} / \mathrm{g}\right)$, with the corresponding poor results for the dehydrogenation step to form benzaldehyde (see Table 1S in supplementary material), while a competing acid catalyzed etherification reaction giving rise to dibenzylether (2) as the main product prevailed (entry 5 in Table 1, Figure 1). In accordance to this observation the catalytic results improved considerably when the metal loading was reduced by half $(0.5 \%)$ (entry 6 , table 1) and the metal dispersion was larger (see Table $1 \mathrm{~S}$ in supplementary material). 
<smiles>c1ccc(COCc2ccccc2)cc1</smiles>

2<smiles>O=C(N=Cc1ccccc1)c1ccccc1</smiles>

3<smiles>CCOC(=O)/C(=C\c1ccccc1)C(C)=O</smiles>

4<smiles>CCOC(=O)c1c(C)nc(C)c(C(=O)OCC)c1-c1ccccc1</smiles>

5

Figure 1. Secondary products detected during the one-pot reaction at $80^{\circ} \mathrm{C}$.

Other secondary products that were detected in this sequential transformation were the imine N-bencilidenurea (3), the aldol condensation product (4) and traces of a dihydropyridine derivative (5) (Fig. 1) described by Hantzsch in 1882. Formation of this product 5 can be accounted for the condensation of the aldehyde, the dicarbonylic compound and ammonia derived from the thermal decomposition of urea [42]. Taking that into account, it appears that the formation of 5 could be completely avoided by keeping the temperature of the multicomponent reaction at $80^{\circ} \mathrm{C}$ (see Fig. 1).

From these results presented in Figure 1 the benefit of using a catalyst with strong acidity when operating at low temperatures is clear. Thus in the search for a solid with strong acid groups $\left(-\mathrm{SO}_{3} \mathrm{H}\right)$ that, at the same time, had a surface area large enough to achieve good metal dispersion we selected the nanocomposite silica-Nafion named SAC-13 [52]. This material, which is produced by the entrapment of nanometer sized Nafion resin particles (having highly acidic fluoro sulphonic acid groups) in a highly porous silica network, has a BET surface area in the range of $150-500 \mathrm{~m}^{2} / \mathrm{g}$ that, in principle, should allow a high metal dispersion. Then $0.25,0.5$ and $1 \%$ weight Pd (see experimental section) was incorporated on the Nafion composite material to obtain three different bifunctional $\mathrm{Pd} / \mathrm{SAC}-13$ catalysts with three different metal loadings for performing the two-step one-pot reaction $(\mathrm{Pd}(0.25 \%) / \mathrm{SAC}-13, \mathrm{Pd}(0.5 \%) / \mathrm{SAC}-13$ and $\mathrm{Pd}(1 \%) / \mathrm{SAC}-13)$.

Among them, $\mathrm{Pd}(0.5 \%) / \mathrm{SAC}-13$ afforded the best catalytic results (entries 7-9, table 1). In fact, the catalytic performance of $\operatorname{Pd}(0.5 \%) / S A C-13$ for steps a and $b$ improved as compared to previous catalysts due to the good metal dispersion achieved on this surface (see characterization data in table 1S, supplementary material).

HRTEM images and STEM-XEDS analysis of $\mathrm{Pd}(0.5 \%) / \mathrm{SAC}-13$ (see Figure $1 \mathrm{~S}$, supplementary material) confirmed the existence of a homogeneous distribution of relatively small palladium particles on the Nafion-silica nanocomposite surface (see characterization data in Table 1S supplementary material). 
In parallel, a high density sulfonic polymer supported onto $\mathrm{SiO}_{2}$ was also prepared, starting from the acid form of a vinylsulfonic monomer [41]. Thus, vinylsulfonic acid was polymerized giving poly(vinylsulfonic acid) (PVS), which was deposited onto a silica surface $\left(\mathrm{PVS} / \mathrm{SiO}_{2}\right)$ providing a new type of solid acid catalyst [41]. It is important to indicate that as in the previous case with commercial Nafion SAC-13 catalyst, this synthetic methodology does not introduce sulfonic acid groups through an individual covalent anchoring, but rather multiple sulfonic groups as a polymer onto the carrier surface. We chose this catalyst because the high polymerizability of the vinylsulfonic monomer and the high acid density of the polymer PVS, that usually results in a high density of catalytically active acid sites on the heterogeneous catalyst [41]. In this case the resulting $\mathrm{Pd}(0.5 \%) / \mathrm{PVS} / \mathrm{SiO}_{2}$ catalyst gave $297 \mathrm{~m}^{2} / \mathrm{g}$ (see Table $1 \mathrm{~S}$, supplementary material).

The catalytic performance of $\mathrm{Pd}(0.5 \%) / \mathrm{PVS}-\mathrm{SiO}_{2}$ for the synthesis of the DHPM derivative 1 was only slightly lower than that obtained with $\operatorname{Pd}(0.5 \%) / \mathrm{SAC}-13$ (entry 10 , Table 1 ). This experimental fact can give the clue for the two greatest demands of this one-pot reaction. On the one hand, a reduced metal particle size for an effective oxidation reaction and on the other strongly acidic centers (as can be sulfonic groups) for an effective multicomponent cyclization to take place. This fact can be corroborated because other catalysts with high Pd dispersion and lower acidity such as $\operatorname{Pd}(0.5 \%) / \mathrm{CeO}_{2}$ and $\mathrm{Pd}(0.5 \%) / \mathrm{ZrO}_{2}$ failed at the level of the cyclization step and gave lower yields of the heterocycle DHPM according to the last two entries of the table 1 (entries 1112, Table 1).

Thus, the final conclusion of this part of the work is that a high metal Pd dispersion on strong solid acids are required for a bifunctional catalyst that can perform successfully the synthesis of dihydropyrimidinone derivatives working at relatively low reaction temperatures. This can be achieved by Pd supported on the composite Nafion (SAC-13).

Three-step one-pot synthesis of DHPM ester 1 through oxidation, cyclocondensation and transesterification reactions.

Since the procedure described above is chemoselective and operates under relatively mild reaction conditions, we thought in extending this protocol to the synthesis of a dihydropirimidinone derivative with therapeutic activity by means of a transterificacion reaction on the newly formed DHPM structure.

For achieving this, benzyl alcohol was oxidized to benzaldehyde in the presence of $\operatorname{Pd}(0.5 \%) / \mathrm{SAC}-13$ at $100^{\circ} \mathrm{C}$. Then benzaldehyde was coupled in situ with the $\alpha, \beta$-ketoester and urea to afford the dihydropyrimidin-2(1H)-one derivative 1 through a cyclocondensation reaction at $80^{\circ} \mathrm{C}$ temperature. Thus, the remaining step would be the transesterification of $\mathbf{1}$ with 
cyclopentanol, which is also catalyzed by acid sites. Following the one-pot strategy described above, catalytic amounts of fresh heteropolyacid phosphotungstic acid PTA within cyclopentanol were incorporated to the reactor and the reaction was carried out at $140^{\circ} \mathrm{C}$ (see experimental section, Scheme 4).

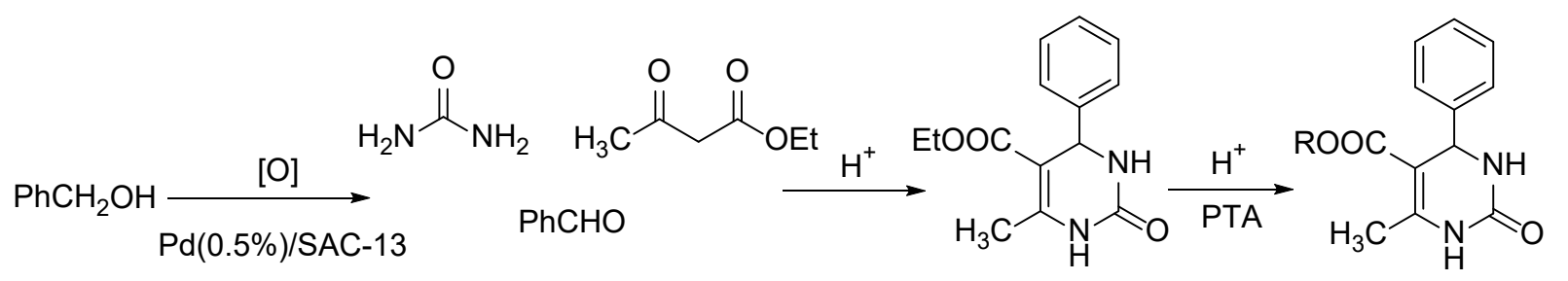

\begin{tabular}{|c|c|c|}
\hline & Compound & Yield(\%) \\
\hline$R=\square$ & 1 & 40 \\
\hline $\mathrm{R}=\mathrm{CH}_{3-}\left(\mathrm{CH}_{2}\right)_{2}-\mathrm{CH}_{2}^{-}$ & 6 & 68 \\
\hline $\mathrm{R}=\mathrm{CH}_{3}-\left(\mathrm{CH}_{2}\right)_{3}-\mathrm{CH}_{2}^{-}$ & 7 & 57 \\
\hline $\mathrm{R}=\mathrm{CH}_{3}-\left(\mathrm{CH}_{2}\right){ }^{-}-\mathrm{CH}_{2}^{-}$ & 8 & 42 \\
\hline $\mathrm{R}=\left(\mathrm{CH}_{3}\right)_{3}-\mathrm{C}-$ & 9 & 20 \\
\hline $\mathrm{R}=\mathrm{Ph}-\mathrm{CH}_{2}^{-}$ & 10 & 20 \\
\hline
\end{tabular}

Scheme 4 One-pot reaction for the synthesis of new DHPM ester derivatives 1, 6-10 catalyzed by $\operatorname{Pd}(0.5 \%)-S A C 13$ and PTA.

It has to be pointed out that the synthesis of this compound has been described to occur in a two separated reaction steps, involving the reaction of cyclopentanol with diketene to afford a ketoester, which will be subjected to an ulterior $\mathrm{BF}_{3}$ catalysed Biginelli condensation with urea and the appropriate aldehyde to give the dihydropirimidinone structure [34] (Scheme 5). 


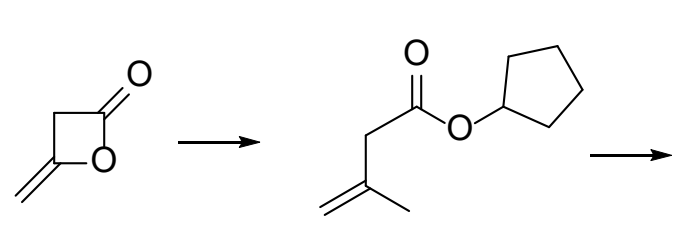

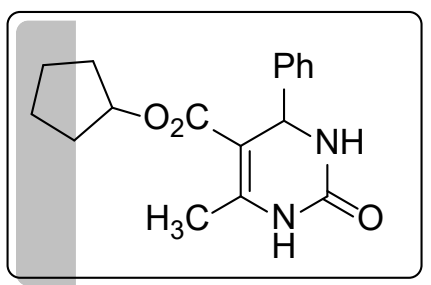

1

THREE STEP ONE-POT ROUTE

$\mathrm{EtO}_{2} \mathrm{C}$<smiles>CCOC(=O)CCC(C)C</smiles><smiles>[CH]C</smiles>

Scheme 5. Classical [34] versus one-pot routes for the synthesis of compound $\mathbf{1 .}$

Through the one-pot strategy the yields of compound 1 were moderated due to the existence of a competing reaction for forming dibenzyl ether. Nonetheless, the final yields of the transesterification compound $\mathbf{1}$ markedly increased when reacting less hindered short chain primary alcohols such as $n$-butanol acting as nucleophile in the one-pot strategy (Scheme 4).

In this line the yield of the transesterification product also decreased when the chain length of the unbranched alcohols was elongated from $n$-butanol to $n$-hexanol as well as when using a benzylic type alcohol or a tertiary alcohol such as tert-butanol (see one-pot synthesis of compounds 6-10 in Scheme 4).

Reusability and recyclability experiments with bifunctional metal/acid catalysts $P d(0.5 \%)$ $S A C 13$.

Given that $\mathrm{Pd}(0.5 \%) / \mathrm{SAC}-13$ afforded the best catalytic results we explored the possibility of recycling and reusing this solid metal/acid catalyst in subsequent runs for the synthesis of DHPM. Then, $\operatorname{Pd}(0.5 \%) / \mathrm{SAC}-13$ which was recovered by filtration at the end of the global process was exhaustively washed with TFT, dried and calcined at $300^{\circ} \mathrm{C}$ for $2 \mathrm{~h}$ under air, and hydrogenated at $100^{\circ} \mathrm{C}$ for $1 \mathrm{~h}$. By following this procedure the solid could be used at least four times with a reasonable activity and selectivity (Fig. 4). 


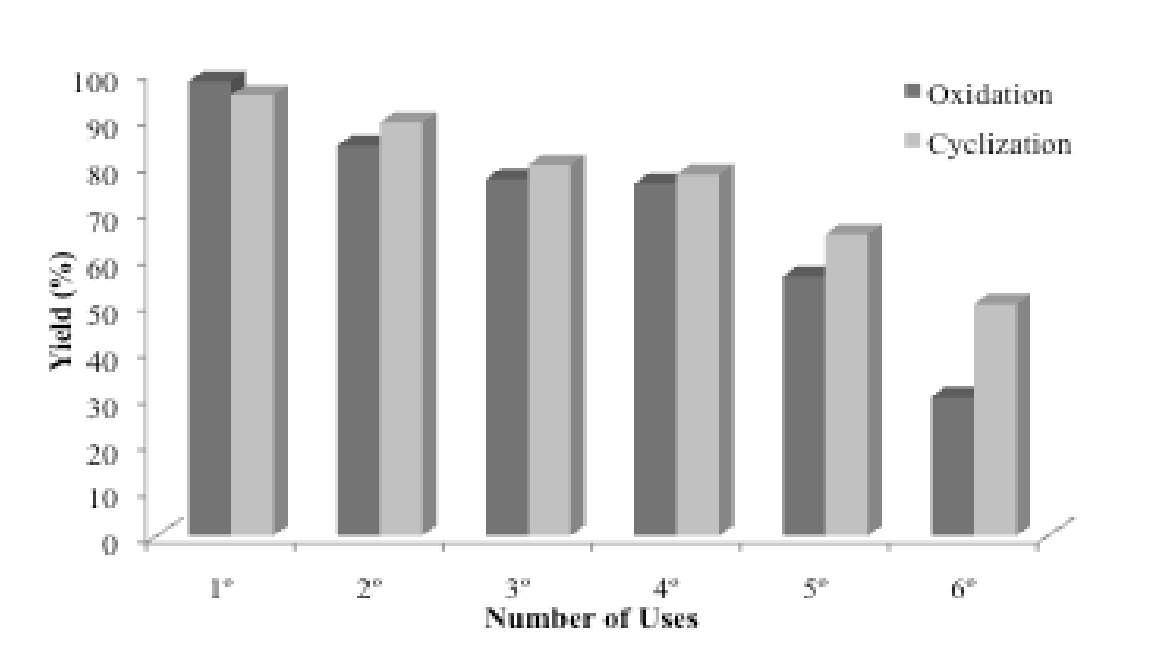

Fig. 4. Reusability experiments for the synthesis of compound $\mathbf{1}$ in the presence of $\operatorname{Pd}(0.5 \%) / \mathrm{SAC}-13$ catalyst.

Nevertheless a gradual decrease in yield was observed in the first and second recycling that has been seen to be due to the leaching of a part of the less strongly attached Pd. It is clear that further catalyst optimization will be necessary to stabilize the Pd and control pore size distribution in the SAC-13 material.

\section{Conclusion}

The catalytic activity of different metal/acid based heterogeneous catalysts was studied in the one-pot synthesis of a DHPM derivative of therapeutic interest.

Then by proper modification of the catalyst and the operating conditions, the production of this molecule could be maximized following a strategy that can substitute a two separated reaction process with intermediate purification steps.

This complex approach, which is based on the use of a multiple catalyst will lead to the direct formation of diverse $\mathrm{C}-\mathrm{C}$ and $\mathrm{C}-\mathrm{N}$ bonds through different successive transformations.

Among all the catalysts studied $\mathrm{Pd}(0.5 \%) / \mathrm{SAC}-13$ has proven to be the most active and selective for the reaction due to a combination of high surface area and strong acidities. Interestingly the catalyst can be regenerated though metal leaching issues should still be improved.

\section{Acknowledgements}

Financial support by the Ministerio de Economia y Competitividad, Programa Severo Ochoa (SEV2016-0683) and Ministerio de Ciencia Innovacion y Universidades, Programa Estatal de Generación de Conocimiento (PGC2018-101247-B-100) are gratefully acknowledged. 


\section{References}

1. C.O. Kappe, Eur. J. Med. Chem. 33, 879, (2000).

2. K.S. Atwal, B.N. Swanson, S.E: Unger, D.M: Floyd, S. Moreland, A. Hedberg, B.C.O. Reilly, J. Med. Chem. 34, 806, (1991).

3. G.C. Rovnyak, K. S. Atwal, A. Hedberg, S. D: Kimball, S. Moreland, J. Z. Gougoutas, B. C. O’ Reilly, J. Schwartz, M. F. Malley, J. Med. Chem. 35, 3254, (1992).

4. J. G . Grover, S. Dzwonczyk, D. M: McMullen, D. E. Normandin, C. S. Parham, P. G. Sleph, S. Moreland, J. Cardiovasc. Pharm., 26, 289, (1995).

5. L. Heys, C.G. Moore, P.J. Murphy, Chem. Soc. Rev. 29, 57, (2000).

6. For a recent review on the subject see: R. Kaur, S. Chaudhary, K. Kumar, M. K. Gupta, R. K. Rawal. Eur. J. Med. Chem. 132, 108, (2017).

7. C.O. Kappe, A. Stadler, Org. React. 63, 1, (2004).

8. C.O. Kappe, Tetrahedron, 49, 6937, (1993).

9. J. Lu, H. Ma, Synlett. 63, (2000).

10. Y. Ma, C. Qian, L. Wang, M. Yang, J. Org. Chem. 65, 3864, (2000).

11. E.H. Hu, D.R. Sidler, U. H. Dolling, J. Org. Chem. 63, 3454, (1998).

12. A. Dandia, M. Saha, H. Taneja, J. Flurine Chem. 90, 17, (1998),

13. B.C. O'Reilly, K.S. Atwal, Heterocycles. 26, 1185, (1987).

14. K.S. Atwal, B.C. O'Reilly, J.C. Gougoutas, M.F. Malley, Heterocycles. 26, 1189, (1987).

15. A. D: Shutalev, E.A. Kishko, N. Sivova, A. Y. Kuznetsov, Molecules. 3, 100, (1998).

16. C.O. Kappe, Eur. J. Med.Chem. 35, 1043, (2000).

17. H. Qu, X. Li, F. Mo, X. Lin, Belstein J. Org. Chem., 9, 2846, (2013).

18. R. K. Sharma, D. Rawat, Inorg. Chem. Commun.,17, 58, (2012).

19. P. M. Kumar, K. S. Kumar, S. R. Poreddy, P. K. Mokakhud, K. Mukkanti, M. Pal, Tetrahedron Lett., 52, 1187, (2011).

20. K. K. Pasunooti, H. Chai, C.N. Jensen, B. K. Gorityala, S. Wang, X. W. Liu, Tetrahedron Lett., 52, 80, (2011).

21. V.P. Srivastava, L. D. S. Yadav, Tetrahedron Lett., 51, 6436, (2010).

22. K. Konkala, N. M. Sabbavarapu, R, Katla, N. Y. V. Durga, V. K. Reddy T., B. L.A. P. Devi, R.B.N. Prasad, Tetrahedron Lett., 53, 1968, (2012).

23. P. Wipf, A. Cunningham, Tetrahedron Lett. 36, 7819, (1995).

24. C.O. Kappe, Bioorg. Med. Chem. Lett. 10, 49, (2000). 
25. R. J. Schmidt, L.J. Lombardo, S. C. Traeger, D. K. Williams, Tetrahedron Lett., 49, 3009, (2008).

26. R.J. Cervasio, J. S. Bello-Forero, J.A. Hernandez-Muñoz, J. Jones, F.M. da Silva, Curr.Org. Synth., 14(5), 715, (2017). (propylene carboxylate green solvent)

27. H. Halinezhad, M. Tajbakhsh, M. Zare, M. Mousavi, Heteroatom Chem., 27(5), 290, (2016). (no solvent)

28. R. Moosavifar, Compt. Rend. Chim., 15(5), 444, (2012).

29. J. Lal, M. Sharma, S. Gupta, P. Parashar, P. Sahu, J. Mol. Catal. A., 352, 31, (2012).

30. V. Dabholkar, K. Badhe, S. Kurade, Curr. Chem. Lett. 6 (2), 77(2017) (Solid catalysts)

31. For a recent review see: R. V. Patil, J. U. Chavan, D. S. Dalal, V. S. Shinde, A. G. Beldar, ACS Comb. Sci., 21, 105, (2019). (solid catalysts)

32. M.J. Climent, A. Corma, S. Iborra, M.J. Sabater, ACS Catal., 4-3, 870, (2014).

33. A. Corma, J. Navas, M. J. Sabater, 108, 1410, (2018).

34. C. Blackburn, B. Guan, J. Brown, C. Cullis, S.M. Condon, T.J. Jenkins, S. Peluso, Y. Ye, R.E. Gimeno, S. Punreddy, Y. Sun, H. Wu, B. Hubbard, V. Kaushik, P. Tummino, P. Sanchetti, D.Y. Sun, T. Daniels, E. Tozzo, S.K. Balani, P. Raman, Bioorg. Med. Chem. Lett, 16, 3504, (2006).

35. A. M. Venezia, R. Murania, G. Pantaleo, V. La Parola, S. Scire, G. Deganello, Appl. Catal. A. Gen., 353, 296, (2009).

36. A. Corma, A. Leyva, H. García, J. Catal., 225, 350, (2004).

37. A. Corma, V. Fornés, S. B. Pergher, US Patent, 6231751, 2001.

38. A. Corma, A., Martinez, V. Martinez-Soria, J. Catal., 200, 259, (2001).

39. A. Corma, V. Fornés, S. Pergher, Nature, 396, 353, (1998).

40. T. Seki, J.D. Grundwalt, N van Vegten, A. Baiker, Adv. Synth. Catal., 350, 691, (2008).

41. T. Okayasu, K. Saito, H. Nishide, M.T.W. Hearn, Chem. Commun., 4708, (2009).

42. A. Hantzsch, Chem. Ber., 14(2), 1637, (1881).

43. S. Carretin, P. Concepción, J.M. Lopez Nieto, V.F. Puntes, A. Corma, Angew. Chem., Int. Ed., 43(19), 2538, (2004),

44. A. Corma. A. Leyva, M.J. Sabater, Chem. Rev., 111, 1657, (2011).

45. A. Corma. T. Rodenas, M.J. Sabater, J. Catal., 279(2), 319, (2011).

46. A. Corma. T. Rodenas, M.J. Sabater, Chem. Eur. J., 16(1), 254, (2010).

47. A. Corma, T. Rodenas, M. J. Sabater, Chem.Sci., 3, 398, (2012).

48. A. Corma, J. Navas, M. J. Sabater, Chem Eur J., 18(44), 14150, (2012).

49. A. Corma, J. Navas, M. J. Sabater, Chem Eur J, 19(51), 17464, (2013).

50. M. J. Climent, A. Corma, S. Iborra, M.J. Sabater, ACS: Catalysis, 4, 870, (2014). 
51. M. J. Climent, A. Corma, S. Iborra, J.D. Vidal, M.J. Sabater, Appl. Catal. A. Gen.. 481, 27, (2014).

52. A. Corma, Curr. Op. Sol. Stat. Mat. Sci., 2(1), 63, (1997).

53. Z. Zhang, W. M. H. Sachtler, H. Chen, Zeolites, 10, 784, (1990).

54. A. Corma, A. Martinez, V. Martínez-Soria, J. Catal., 200, 259, (2001).

55. R. Pal, T. Sarkar, S. Khasnobis, Arkivoc, (i), 570, (2012).

56. T. Seki, J.D. Grunwaldt, N. van Vegten, A. Baiker, Adv. Synth. Catal., 350, 691, (2008). 